\title{
Impacto Econômico dos Inoculantes na Soja: Uma Análise Insumo-Produto
}

\author{
Jaim José da Silva Junior ${ }^{1}$; Bruno César Brito Miyamoto ${ }^{2}$; Jamile de Campos Coleti ${ }^{3}$; Jose Maria Ferreira \\ Jardim da Silveira ${ }^{4}$ \\ 1 - UnB/Faculdade de Agronomia e Medicina Veterinária. Professor Adjunto do curso de Gestão de \\ Agronegócios na Universidade de Brasília. Doutor em Teoria Econômica pela Universidade Estadual de \\ Campinas. Estuda temas relacionados ao desenvolvimento rural e agrícola, com ênfase em pesquisa e \\ inovação nos mercados de insumos agrícolas. Trabalha com organização e avaliação de programas de \\ investimento em $\mathrm{P} \& \mathrm{D}$ agrícola. \\ 2 - Instituto Federal de Educação, Ciência e Tecnologia do Rio Grande do Sul, IFRS - Campus Feliz. \\ Professor do Instituto Federal de Educação, Ciência e Tecnologia do Rio Grande do Sul (IFRS) . Possui \\ graduação em Administração pela Unesp e doutorado em Desenvolvimento Econômico pela Unicamp. \\ Atua na área de economia agrícola e dos recursos naturais especificamente nos temas: avaliação de \\ impactos econômicos, biotecnologia agrícola, inovação tecnológica e mudanças climáticas. \\ 3 - Faculdade Anhanguera de Piracicaba. Possui graduação em Gestão do Agronegócio e em \\ Administração (UNICAMP) e mestrado em Desenvolvimento Econômico (UNICAMP) sendo sua \\ dissertação indicada ao Prêmio SOBER. Atualmente é doutoranda no programa de Desenvolvimento \\ Econômico no Instituto de Economia da UNICAMP. Trabalhou no Grupo de Pesquisa e Extensão \\ ESALQ-Log como pesquisadora. Atua nas seguintes áreas: administração, agronegócio, comercialização \\ de commodities e logística agroindustrial. Foi bolsista de doutorado visitante (scholar) no Agribusiness \\ and Agricultural Economics Department da University of Manitoba (Canadá). \\ 4 - Universidade Estadual de Campinas, Instituto de Economia. Professor Livre Docente IE-Unicamp \\ (2014). Membro do Conselho Científico do Núcleo Interdisciplinar de Pesquisas em Energia- NIPE da \\ UNICAMP, Pesquisador do Núcleo de Economia Agrícola e Ambiental do IE/Unicamp e professor \\ Associado da Universidade Estadual de Campinas. Membro do Comitê Científico do International \\ Consortium of Bioeconomy Research - ICABR, desde final de 2012. (www.icabr.org.br). Áreas de \\ pesquisa: economia de redes, economia da inovação tecnológica, modelos baseados em agente. Realiza \\ trabalhos na área de organização industrial, bioenergia e inovação tecnológica na agricultura.
}

\section{Resumo}

O presente trabalho avalia o impacto econômico dos inoculantes no cultivo de soja, considerando tanto seus efeitos diretos como os indiretos sobre o produto interno bruto brasileiro. O modelo utilizado tem como base a matriz insumo produto da economia brasileira de 2006, e avalia de forma empírica o custo de oportunidade da substituição dos fertilizantes químicos nitrogenados. Os resultados indicam que a fixação biológica de nitrogênio soja incrementou o produto interno bruto brasileiro em aproximadamente R\$ 7 bilhões no ano de 2006. O valor diz respeito principalmente ao ganho de competitividade internacional, e a potencial perda de exportações resultante do abandono da inoculação. Destaca-se que para além dos impactos econômicos, o uso dos inoculantes reduz as emissões de gases de efeito estufa na produção agrícola e, com isso, contribui para o desenvolvimento econômico sustentável.

Palavras-Chave: inoculantes; fertilizantes nitrogenados; matriz insumo-produto.

Classificação JEL: Q16, Q55. 


\section{Economic Impact of Soy Inoculants: An Input-Output Analysis}

Abstract

The present study evaluates the economic impact of inoculants on soybean cultivation, considering both their direct and indirect effects on Brazilian gross domestic product. The model used is based on the matrix input product of the Brazilian economy of 2006, and empirically evaluates the opportunity cost of replacing nitrogenous chemical fertilizers. The results indicate that the biological fixation of soybean nitrogen increased Brazilian gross domestic product by approximately $R \$ 7$ billion in 2006. The value is mainly related to the gain in international competitiveness and the potential loss of exports resulting from the abandonment of inoculation. It should be noted that in addition to the economic impacts, the use of inoculants reduces greenhouse gas emissions in agricultural production and, therefore, contributes to sustainable economic development.

Keywords: inoculants; nitrogen fertilizers; input-product matrix.

JEL classification: Q16, Q55. 


\section{1 - INTRODUÇÃO}

O objetivo geral deste estudo é discutir a inserção da biotecnologia moderna no sistema de produção agrícola, com foco na nutrição vegetal. Nas lavouras brasileiras de soja, a tecnologia da inoculação é capaz de suprir toda a demanda das plantas por nitrogênio através da fixação biológica do nutriente. Com isso, o uso dos inoculantes permite a substituição integral dos fertilizantes nitrogenados no cultivo da soja no Brasil e constitui um processo de destruição criativa.

A metodologia adotada segue as análises insumo-produto de avaliação dos impactos diretos e indiretos sobre o valor bruto da produção, emprego e valor adicionado bruto, causados por mudanças nos coeficientes técnicos de produção ou em parâmetros exógenos ao modelo. Os impactos são avaliados a partir da matriz insumo-produto (MIP) da economia brasileira do ano de 2006. Este trabalho pretende contribuir de forma original às análises insumo produto da agricultura e pecuária nacional. Nesse intuito, a MIP adotada classifica as atividades econômicas em 58 setores e apresenta desagregados os setores de interesse da pesquisa: soja e fertilizantes nitrogenados.

Os argumentos desenvolvidos buscam testar a hipótese acerca da importância dos inoculantes para o cultivo da soja no Brasil. As mudanças nos coeficientes técnicos de produção problematizam a substituição de insumos no setor produtor de soja em grão. Parâmetros exógenos como a difusão de cultivares de maior produção por hectare e a eficiência da fixação biológica de nitrogênio (FBN) aderem dinamismo ao modelo. Conforme será discutido, a difusão da fixação biológica de nitrogênio impactou a produtividade das lavouras, com desdobramentos sobre a competitividade internacional da soja brasileira. No cumprimento dos objetivos traçados o trabalho está divido em cinco seções.

Após a introdução, o segundo item discute a substituição dos fertilizantes nitrogenados por inoculantes na cultura da soja no Brasil. O terceiro item trata de apresentar o modelo insumo-produto adotado neste trabalho, assim como da sua aplicação nos cenários propostos ao longo do item. Cada cenário compreende um conjunto de suposições sobre o funcionamento da economia, com impactos diretos nos setores produtores de soja e fertilizantes. O quarto item do artigo faz a análise dos resultados obtidos pelo modelo. Nas considerações finais serão retomadas algumas questões relacionadas aos inoculantes e aos fertilizantes nitrogenados, e lançadas perspectivas para estudos futuros sobre o tema. 
A despeito da fixação biológica de nitrogênio, o uso dos inoculantes resulta também no enriquecimento da matéria orgânica do solo, em melhorias no padrão de germinação das sementes, em maior adsorção de nutrientes e no controle de estresses hídricos e térmicos do solo. Em conjunto, tais fatores possibilitam a prática de atividades agrícolas mais sustentáveis, sem comprometer o nível de produção. Porém, não são capazes de impulsionar a difusão dos inoculantes para outras culturas como milho, cana e algodão. Afirma-se que a incorporação destes benefícios proporcionados pela inoculação ao sistema agrícola requer a construção de mecanismos de avaliação dos impactos dos inoculantes que extrapolem o âmbito dos mecanismos de mercado.

\section{2 - SUBSTITUIÇÃO DOS FERTILIZANTES NITROGENADOS POR INOCULANTES}

\subsection{Os Inoculantes e o seu uso}

De acordo com a definição do Ministério da Agricultura, Pecuária e Abastecimento (MAPA), o inoculante é todo produto que contem microrganismos favoráveis ao crescimento de plantas. Estes microrganismos de importância agrícola ${ }^{5}$ podem ser fungos, bactérias, protozoários, ácaros, dentre outros. Nesse sentido, os inoculantes podem desempenhar diversas funções favoráveis à maior eficiência da produção agrícola. No Brasil, os inoculantes mais comercializados são compostos por bactérias capazes de realizar a fixação biológica do nitrogênio (rhizobium). Produtos compostos por fungos que estimulam o sistema radicular das plantas (micorrizas arbusculares) são produzidos em menor escala.

O Brasil ocupa posição de destaque no domínio das práticas científicas combinadas na produção de inoculantes. Essa posição foi conquistada através de anos de pesquisas científicas voltadas para o melhor aproveitamento das vantagens naturais do país: clima tropical e subtropical e grande diversidade biológica (Silveira, Borges e Buainain, 2005). Os programas de pesquisa dedicados ao desenvolvimento de inoculantes atuam na fabricação de produtos para culturas como feijão, trigo, soja, milho, cana-de-açúcar, dentre outras. É importante ter em mente que os microrganismos são específicos para cada tipo de planta. Isto é, um inoculante de sucesso na soja não irá obter resultados semelhantes se aplicado no milho. Tal fato revela parte da complexidade envolvida na difusão desses insumos. Em função dos objetivos do trabalho, discutiremos com maior profundidade apenas os inoculantes da soja.

5 - Para maiores informações sobre microrganismos de importância agrícola e suas aplicações na agricultura brasileira ver, Hungria (1994). 
Como a soja não é nativa do Brasil, os solos brasileiros não possuem bactérias indígenas fixadoras de nitrogênio apropriadas às variedades cultivadas no país. Os primeiros estudos de avaliação de estirpes de bactérias importadas dos EUA e da Austrália foram conduzidos na seção de bacteriologia agrícola do Instituto Agronômico de Campinas (IAC) na década de 1920. Em 1930, ocorreu a primeira produção e distribuição de inoculantes para agricultores brasileiros interessados no cultivo de soja (Hungria et al.,2006). No final da década de 1950, a fixação biológica de nitrogênio foi institucionalizada como um dos parâmetros considerados no programa brasileiro de melhoramento da soja (Dobereiner, 1997). Desde então, linhas e grupos de pesquisa concentram esforços na seleção de estirpes de bactérias adaptadas às cultivares mais produtivas de soja e aos tipos de solos brasileiros.

Assim como se selecionam plantas e animais por suas características produtivas, também existe um enorme trabalho para selecionar estirpes de bactérias mais produtivas a fim de incorporá-las ao inoculante. O processo de fabricação dos inoculantes tem início, portanto, no laboratório. As estirpes previamente selecionadas são submetidas a testes de campo em diversas regiões do Brasil. A fase seguinte, experimentação em rede das estirpes elegidas, requer que o acompanhamento dos testes de campo seja feito no mínimo por dois anos e em duas regiões de plantio distintas. Centros de pesquisa como a Embrapa Soja, a Embrapa Cerrado, a Embrapa Agrobiologia, a Embrapa Centro-Oeste, a FEPAGRO e o IAC, fazem parte desta rede de testes.

As empresas produtoras de inoculantes recebem as estirpes e tratam principalmente da reprodução em larga escala destas bactérias. A fase final do crescimento bacteriano ocorre em tanques de fermentação, resultando em um líquido com elevada concentração de bactérias. O líquido dos tanques de fermentação é então misturado à turfa para produção de inoculante em pó, ou aos protetores celulares para a obtenção do inoculante líquido. Ao término deste complexo processo de fabricação, os inoculantes estão prontos para aplicação nas sementes. $\mathrm{O}$ uso dos inoculantes pelos agricultores é a etapa mais simples da cadeia. De início, o produto final é misturado às sementes de soja em tambores rotatórios ou máquinas de tratamento de sementes. Vale ressaltar que a inoculação deve ser realizada no intervalo de tempo mais próximo possível da semeadura. Depois de cumpridas todas estas etapas, o sucesso da colonização do solo por bactérias fixadoras de nitrogênio garante a quantidade de nitrogênio requerida através da fixação biológica do nutriente, dispensando o uso de fertilizantes nitrogenados. 


\subsection{O Papel do Nitrogênio na Nutrição Vegetal e os Fertilizantes Nitrogenados.}

Em condições naturais, percebidas em florestas nativas ou terras inexploradas, a maior parte dos elementos requeridos para a nutrição adequada às plantas encontra-se previamente disponível no solo. Isto ocorre porque os nutrientes liberados por plantas em estágio de decomposição enriquecem a fertilidade natural do solo e sustentam o tipo de cobertura vegetal apresentado. No entanto, a lógica de produção das lavouras comerciais não compreende a etapa de decomposição das plantas. Por esse motivo, a produção agrícola não restitui ao solo os alimentos consumidos na formação das lavouras. Quer dizer, a continuidade da produção agrícola acarreta no esgotamento da fertilidade natural do solo e compromete o rendimento das produções subsequentes.

O nitrogênio constitui vários compostos essenciais às plantas, com destaque para os aminoácidos, os ácidos nucléicos e a clorofila (Novais et al.,2007). Nota-se que a deficiência de nitrogênio proporciona menor síntese de clorofila, inibindo o aproveitamento de luz solar como fonte de energia no processo fotossintético. Desse modo, a insuficiência de nitrogênio compromete a habilidade da planta de executar funções essenciais como a absorção de nutrientes e o incremento de proteínas. Pode-se afirmar que a quantidade de nitrogênio requerida pelas plantas é elevada e sustenta o nível de produção por hectare das plantações.

À exceção da soja brasileira, a quantidade de nitrogênio removido pelas demais culturas é reposta ao solo principalmente via a aplicação de fertilizantes nitrogenados. No cálculo da recomendação de adubação fatores como a fertilidade natural do solo, a concentração de nitrogênio nos fertilizantes e a taxa de aproveitamento do fertilizante influenciam na quantidade de adubos nitrogenados demandada. Atualmente, a ureia representa o fertilizante nitrogenado mais utilizado pelos agricultores. Não obstante, outros produtos já ocuparam esta posição.

O salitre minado de depósitos naturais chilenos, exportado para Europa e Estados Unidos, foi o primeiro fertilizante nitrogenado comercializado no mundo. A partir de 1900, os esforços pela fixação do nitrogênio atmosférico obtiveram êxito através da aplicação de conhecimentos químicos. Em 1913 na Alemanha, Haber e Bosch deram origem à moderna indústria de fertilizantes nitrogenados, através da síntese direta da amônia a partir de nitrogênio e hidrogênio, usando o coque como matéria-prima (IPT, 1990). Nos Estados Unidos a fabricação de amônia sintética teve início em 1921, ainda na fase 
ascendente do ciclo de vida deste produto. De forma geral, o aumento da capacidade de produção das plantas industriais de amônia foi marcado por "saltos" na escala e possibilidades de substituições de matéria prima.

A tecnologia empregada na indústria brasileira de fertilizantes nitrogenados foi licenciada por firmas com o domínio da base de conhecimento do setor. Sem embargo, a formação da indústria nacional de fertilizantes nitrogenados dispensou as etapas de pesquisa e desenvolvimento de produtos e processos. Estão instaladas no país cinco plantas produtoras de amônia em larga escala, todas integradas à produção de ureia.

Após entrar em operação o último complexo produtor de amônia e ureia instalado no país, no início da década de 1980, a produção nacional de fertilizantes nitrogenados esteve perto de satisfazer toda a demanda por nitrogênio na agricultura brasileira. Desde então, as dinâmicas de expansão da área cultivada e dos avanços nos programas de melhoramento genético das cultivares brasileiras alteraram o patamar de importação de fertilizantes nitrogenados.

De acordo com dados da associação nacional para difusão de adubos (ANDA, 2009), a importação de fertilizantes nitrogenados em 2006 correspondeu a setenta por cento do consumo aparente destes insumos no Brasil. Uma análise comparativa do panorama internacional revela a escassez brasileira de investimentos no setor, que perdura desde a década de 1980 até os dias de hoje. Na China a primeira planta de larga escala para produção de amônia só foi instalada em 1979. Atualmente este país é o maior produtor mundial de nitrogenados, e possui em seu território vinte e nove plantas de produção de amônia em larga escala (IFA, 2009). A Indonésia inaugurou sua primeira unidade para produção de amônia em 1974, atualmente possui treze unidades no total e atinge níveis de produção três vezes superior à brasileira (IFA, 2007).

Nesse contexto, o aumento na oferta brasileira de nitrogênio necessário para reduzir a dependência da agricultura nacional de adubos importados trata-se de um esforço conjunto de todas as áreas do conhecimento envolvidas na nutrição vegetal. Ações tomadas para a descoberta de fertilizantes mais eficientes, instalação de novas unidades de produção e o fortalecimento das demais fontes provedoras de nitrogênio às plantas compartilham do mesmo objetivo, sustentar o nível de produção e rendimento da agricultura nacional. 


\section{3 - MATERIAIS E MÉTODOS}

\subsection{O Modelo Teórico de Leontief}

Análises da produção de bens com base em modelos de insumo-produto adotam uma série de pressupostos sobre o funcionamento da economia. Talvez o mais relevante seja aquele que assume o nível de produção em uma dada economia como o somatório da quantidade de bens produzidos e consumidos durante o período avaliado. A primeira abordagem da interdependência entre as atividades econômicas remete ao trabalho de Quesnay, no final do século XVIII, sintetizado na figura do Tableau Économique.

Kurz e Salvadori (2000) apresentam as raízes teóricas do modelo insumo-produto e ressaltam como esta ferramenta analítica foi paralelamente desenvolvida por economistas de diferentes correntes teóricas. Sraffa em Cambridge (UK) e Leontief em Berlim representaram a estrutura econômica através de um sistema de equações capaz de traduzir as quantidades observáveis de bens produzidos e consumidos durante o período avaliado.

Cabe ressaltar que entre Sraffa e Leontief não houve qualquer tipo de intercâmbio de ideias e, mesmo assim, os autores alcançaram resultados iniciais semelhantes. Conforme apontam Kurz e Salvadori (2000), Sraffa permaneceu preocupado em formular uma abordagem alternativa à teoria marginalista. Já Leontief demonstrou maior interesse na aplicação de sua teoria em problemas práticos, para isso desenvolveu as ferramentas analíticas do modelo insumo-produto. De acordo com Miller e Blair o modelo derivado da teoria de Leontief pode ser assim descrito:

In its most basic form, an input-output model consists of a system of linear equations, each one of which describes the distribution of an industry's product throughout the economy. Most of the extensions to the basic input-output framework are introduced to incorporate additional detail of economic activity, such as over time or space, to accommodate limitations of available data or to connect inputoutput models to other kinds of economic analysis tools (Miller e Blair,2009,pg.1).

As matrizes insumo-produto são construídas a partir do valor monetário correspondente ao fluxo de produtos entre as atividades econômicas realizadas em região e período específico. Aos valores destas transações interindustriais são acrescidas as vendas de produtos aos consumidores externos aos setores 
industriais. Famílias, governo e exportações são tratados como elementos exógenos. No modelo de Leontief, a produção total da economia $(X)$ é o resultado do somatório entre a produção destinada para o consumo intermediário dos diferentes setores industriais $(Z)$, e a demanda exógena $(Y)$.

Os trabalhos realizados com base em modelos insumo-produto têm como propósito fundamental quantificar as variações na produção total provocadas, ou por mudanças no padrão de consumo intermediário ou na magnitude da demanda final. A transformação no consumo intermediário é tratada no modelo como uma mudança na tecnologia de produção do setor em que ocorre. Este aparato é capaz de avaliar como transformações nas compras setoriais, ou nos componentes exógenos, repercutem em todas as atividades econômicas.

Um dos pressupostos básicos do modelo de Leontief assume que o fluxo de bens entre dois setores, do setor $i$ para o setor $j$, está diretamente relacionado à produção total do setor $j$. Isto é, a quantidade de insumos produzidos no setor $i$ requerida para se obter um dado nível de produção total no setor $j$ pode ser expressa através do conceito de coeficiente técnico. Miller e Blair (2009) definem o coeficiente técnico do seguinte modo:

$$
a_{i_{j}}=\frac{Z_{i j}}{X_{j}}
$$

Onde $Z_{i j}$ expressa as vendas intersetoriais do setor $i$ ao setor $j$, e $X_{j}$ a produção total do setor $j$. A matriz de fluxos interindustriais de bens $(Z)$ e o vetor de produção total $(x)$ oferecem as informações necessárias para o cálculo da matriz de coeficientes técnicos diretos $(A)$. Desse modo, o conjunto de equações simultâneas que simula os fluxos intersetoriais e a demanda exógena no modelo insumoproduto de Leontief pode ser sistematizado da seguinte maneira:

$$
X=A x+y
$$

Resolvendo a equação (2), se obtém a seguinte representação:

$$
\begin{gathered}
X=L y \\
L=(1-A)-1
\end{gathered}
$$

No qual $L$ é uma matriz de dimensões $(n \times n)$ geralmente denominada como a matriz inversa de Leontief, ou a matriz de coeficientes técnicos diretos e indiretos. Através da matriz $L$, os impactos de transformações setoriais são propagados para todos os setores da economia de acordo com a magnitude das relações econômicas entre as atividades. De posse da teoria básica acerca do modelo insumo-produto 
passamos à construção das matrizes requeridas para sua aplicação.

\subsection{Organização dos dados de Insumo-Produto}

Para trabalhar com matrizes de insumo-produto é preciso saber construí-las. A origem dos números divulgados nas matrizes, a metodologia de mensuração das informações ali presentes, e os conceitos adotados em tais tarefas devem ser do conhecimento de todos os candidatos à aplicação do modelo básico de Leontief. Nessa empreitada, a familiaridade com o sistema de contas nacionais torna-se condição imprescindível.

As tarefas fundamentais das contas nacionais são classificar a imensa variedade de agentes, os fluxos econômicos e os estoques de ativos e passivos num número limitado de categorias essenciais e integrálas num esquema contábil de forma a obter uma representação completa e clara, ainda que simplificada, do funcionamento da economia. O esquema contábil das contas nacionais tem sua lógica centrada na ideia de reproduzir os fenômenos essenciais da vida econômica de um país: produção de bens e serviços; geração, alocação e distribuição da renda; consumo e acumulação (IBGE, 2008).

A construção das matrizes que compõem o sistema de insumo-produto utiliza informações contidas na tabela de recursos e usos (TRU) do sistema de contas nacionais. As tabelas de produção - matriz V - e de usos de bens e serviços - matriz U - da TRU apresentam uma análise detalhada da produção por atividade econômica e dos fluxos de bens e serviços por tipo de produto. Entretanto, dada a hipótese da teoria de Leontief da inexistência de subprodutos dentro do processo produtivo, torna-se necessária a combinação dos dados presentes na TRU com vistas a aplicação prática. Sendo Q o vetor de produção total de um produto, e X o vetor de produção total de um setor na economia temos que:

$$
\begin{aligned}
& B=U^{x}-1 \\
& D=V^{Q}-1
\end{aligned}
$$

No enfoque setor por setor com a tecnologia baseada na indústria:

$$
X=(I-D B)-1 Y
$$

A hipótese da tecnologia baseada na indústria assume que um setor pode alterar o seu consumo intermediário sem perder participação nos mercados em que atua. Trata-se da hipótese mais comum entre os modelos insumo-produto em função da proximidade com a realidade. No qual o produto das matrizes 
$D U$ equivale à matriz $(Z)$ de consumo intermediário e o das matrizes $D B$ representa a matriz $(A)$ de coeficientes técnicos. Desse modo, as matrizes insumo-produto integradas à concepção dos agregados econômicos presente nos manuais do Sistema de Contas Nacionais das Nações Unidas tornam possíveis abordagens comparativas de atividades econômicas realizadas em diferentes países.

No Brasil, a primeira matriz insumo-produto construída a partir dos dados do Sistema de Contas Nacionais foi publicada em $1989^{6}$, e retratou a economia do país com base na estrutura vigente no ano de 1980. Atualmente as contas nacionais brasileiras são divulgadas em versão preliminar, no ano seguinte ao ano de referência $(t+1)$. Há uma primeira revisão desta versão preliminar no ano posterior à sua publicação, e somente três anos após o de referência $(t+3)$ as contas nacionais brasileiras são divulgadas na versão final. No entanto, não é necessário esperar até a divulgação dos dados finais para se trabalhar com as informações do sistema de contas nacionais.

Guilhoto e Sesso Filho (2005) desenvolveram uma metodologia para estimação da matriz insumoproduto a partir dos dados preliminares das contas nacionais. De fato, esta metodologia foi desenvolvida para a estimação da matriz U. Isto porque a tabela de usos de bens e serviços da TRU apresenta valores a preços de mercado (ou preço do consumidor), e por esse motivo engloba além do preço básico, os valores das importações, os impostos indiretos líquidos e as margens de comércio e transporte. A matriz V pode ser obtida diretamente da tabela de produção do sistema de contas nacionais.

A matriz insumo produto utilizada neste trabalho foi estimada com base na metodologia de Guilhoto e Sesso Filho (2005). A desagregação dos setores de interesse da pesquisa, soja e fertilizantes, apoiou-se na metodologia desenvolvida por Furtuoso e Guilhoto (2003). Os valores monetários das atividades econômicas praticadas pelos setores produtores de soja e fertilizantes acompanha aqueles estimados por Guilhoto et al.(2007). O próximo item trata da aplicação prática de todos os argumentos desenvolvidos até aqui.

\subsection{Modelo para Avaliação Econômica dos Inoculantes na Soja}

Destarte, o modelo avalia quantitativamente o custo de oportunidade referente à inoculação das sementes de soja. Isto porque a MIP brasileira do ano de 2006 já apresenta incorporada em sua estrutura tecnológica o consumo de inoculantes. Em função disso, o exercício desenvolvido neste trabalho tem início com a substituição dos gastos com inoculantes do setor produtor de soja em grãos pelo valor monetário dos fertilizantes nitrogenados necessários para suprir a quantidade de nitrogênio requerida pelas plantações. 
6 - Demais matrizes insumo-produto da economia brasileira já haviam sido formuladas com base em informações de diferentes origens. Para um histórico detalhado das matrizes insumo-produto brasileiras ver, Guilhoto et al. (2008).

Embora aparentemente complexo, o raciocínio é simples e trata de verificar os impactos sobre a economia nacional de uma perda de eficiência na fixação biológica de nitrogênio realizada pelos inoculantes, via substituição deste insumo pelos adubos nitrogenados. Sabe-se que fatores exógenos como a necessidade de nutrientes das plantas, os investimentos na expansão da capacidade nacional instalada de produção de fertilizantes nitrogenados e o nível de eficiência dos adubos nitrogenados influenciam diretamente os resultados obtidos. No intuito de capturar a dinâmica destes parâmetros exógenos, os exercícios realizados têm por base 3 cenários distintos, conforme exposto na tabela 01 . Em todos os cenários os valores monetários da dose dos inoculantes, da tonelada de ureia no mercado nacional, assim como os percentuais de concentração de nitrogênio na ureia e da efíciência da ureia são mantidos constantes.

Tabela 01 - Cenários adotados no modelo.

\begin{tabular}{llll}
\multirow{2}{*}{ Parâmetros } & \multicolumn{3}{c}{ Cenários } \\
\cline { 2 - 4 } & Básico & Competitivo & Máximo \\
\hline Produção de Soja por hectare & 2.800 quilos & 4.000 quilos & 8.000 quilos \\
\hline Demanda de Nitrogênio por hectare de soja & 224 quilos & 320 quilos & 640 quilos \\
\hline Eficiência da FBN & $0 \%$ & $50 \%$ & $0 \%$ \\
\hline Produção Nacional de Adubos/Consumo Aparente & $100 \%$ & $100 \%$ & $35 \%$ \\
\hline
\end{tabular}

Fonte: Elaboração Própria.

O cenário básico problematiza a substituição dos inoculantes no setor produtor de soja quando satisfeita integralmente pelo acréscimo na oferta nacional de fertilizantes nitrogenados. Quer dizer, no cenário básico adota-se a hipótese de substituição integral dos inoculantes por fertilizantes nitrogenados. Nesse quadro o nível de produção de soja por hectare plantado reflete a produção média do ano de 2006, divulgada nas séries históricas de safras da CONAB. Com efeito, este é o cenário de referência para o estudo, sendo que os demais cenários conferem dinamismo ao modelo.

O cenário competitivo simula um aumento no nível de produção de soja por hectare, resultado esperado dos programas de melhoramento genético das cultivares brasileiras. Plantas com maior capacidade de produção demandam inevitavelmente quantidades superiores de nutrientes. A taxa de 50\% 
para a eficiência da FBN representa o saldo médio da inoculação praticada em países exportadores de soja. Tal parâmetro tem como base os estudos de BIOFAG (2007) que avalia o "estado da arte" da inoculação da soja em países da Ibero-América, Unkovich e Pate (2000) que apresentam o uso deste produto nas plantações australianas, Gan et al.(2002) que discutem a inoculação na agricultura da China e Van Kessel e Harthey (2000) que avaliam a inoculação da soja nos Estados Unidos.

O cenário máximo simula o impacto econômico dos inoculantes com base na hipótese de que a sojicultura brasileira opera no maior nível possível de produção por hectare. De acordo com Hungria et al. (2007), o potencial genético de produção da soja é estimado em aproximadamente 8.000 quilos por hectare. Nesse cenário assumimos que a estrutura tecnológica do setor produtor de soja dispensa o uso de inoculantes. Quer dizer, em um cenário de maior produção por hectare possível, que faz uso integralmente de fertilizantes nitrogenados, qual é o impacto econômico da inoculação. A relação produção nacional consumo aparente de nitrogenados é reduzida para $35 \%$. O percentual avalia quanto do acréscimo na oferta nacional de nitrogenados verificada no cenário básico é capaz de suprir a demanda por nutrientes do cenário máximo.

Cabe ressaltar que em todas as simulações a taxa de eficiência agronômica da ureia (principal fertilizante nitrogenado) adotada foi de $60 \%$. Tal condição reflete a ocorrência de fenômenos recorrentes na agricultura tropical e subtropical como a lixiviação do nitrato e a volatilização da amônia, que repercutem em perdas do nitrogênio depositado no solo (IFA; IPI, 2006; Novais et al;2007). Além disso, a ureia contém concentração de $46 \%$ de nitrogênio. Como resultado destas ponderações, a quantidade de ureia recomendada para suprir a demanda de 100 quilos de nitrogênio é de 362 quilos do fertilizante.

O valor monetário da demanda por nitrogênio nas lavouras brasileiras de soja é estimado com base em informações sobre a quantidade de nutrientes retirados do solo na colheita. FAO; IFA, (2006, pg.24) e Novais et al.; (2007, pg.438) indicam que para cada tonelada de soja colhida são retirados 80 quilos de nitrogênio do solo. O preço da tonelada do adubo nitrogenado (ureia) utilizado neste cálculo encontra-se disponível no anuário estatístico do setor de fertilizantes (ANDA, 2006). No ano de 2006, o preço médio anual da tonelada de ureia comercializada no mercado nacional foi de $\mathrm{R} \$ 480$. A figura 03 apresenta de forma esquemática os pressupostos e a dinâmica do modelo insumo produto utilizado no estudo. 
Quadro 1 - Modelo Insumo Produto proposto.

$\begin{array}{ll}\text { Acréscimo no } & \text { Acréscimo } \\ \text { consumo } & \text { na } \\ \text { intermediário } & \text { capacidade } \\ \text { e maior gasto } & \text { nacional } \\ \text { com adubos } & \text { instalada de } \\ & \text { adubos }\end{array}$

$1^{\text {a }}$ Choque

Substituição dos

Inoculantes por

adubos

nitrogenados

Resultado Final:

Impactos no

Valor Bruto da

Produção,

Emprego e valor

adicionado bruto

da Economia

Nacional
Setor

Produtor Setor Produtor

de Soja $\rightarrow$ de Adubos e

em Fertilizantes
Setor

Produtor

de Soja

em

Grãos

\section{$2^{\circ}$ Choque}

Redução na

demanda de soja

devido ao

repasse integral

dos aumentos no

custo de

produção aos

preços.

Fonte: Elaboração Própria.

O resultado final do modelo é obtido a partir de duas simulações. De início são avaliados os impactos causados pela substituição dos inoculantes no setor produtor de soja. O exercício contrafactual analisa os impactos na demanda de soja causados pelo acréscimo no custo de produção. Cabe ressaltar que as informações não correspondem ao valor da produção do complexo da soja (grãos, óleo e farelo), e tratam somente do setor agrícola produtor de soja em grãos.

A magnitude do " $1{ }^{\circ}$ choque" depende do quanto a demanda adicional de nitrogenados será satisfeita pela produção nacional destes insumos. Na metodologia de análise proposta por Miller e Blair (2009, pg.637) a entrada de novas firmas em indústrias estabelecidas é avaliada a partir das relações inter e intraindustriais pré-existentes. Em uma economia com n setores, o incremento na capacidade do setor de fertilizantes (setor f) irá repercutir diretamente nos demais setores do seguinte modo:

$$
\left[\begin{array}{c}
a_{1 f} X_{f} \\
a_{2 f} X_{f} \\
a_{3 f} X_{f} \\
\vdots \\
a_{n f} X_{f}
\end{array}\right]
$$


Onde $X_{f}$ representa o valor monetário do acréscimo na produção do setor de fertilizantes causado pela substituição de insumos no setor da soja. Os coeficientes técnicos $a_{1 f}, a_{2 f} \ldots a_{n f}$, espelham a estrutura tecnológica do setor de adubos. A propagação do "choque" inicial em toda a economia é simulada pela expressão (9), na qual $\Delta X$ representa o vetor de variações no valor bruto da produção (VBP) setorial. A soma das linhas de $\Delta X$ indica a variação no VBP total da economia.

$$
\left[\begin{array}{c}
a_{1 f} X_{f} \\
a_{2 f} X_{f} \\
a_{3 f} X_{f} \\
\vdots \\
a_{n f} X_{f}
\end{array}\right]=\Delta X=L
$$

O 2 “choque" é introduzido no modelo através da equação:

$$
\Delta X=L \Delta Y
$$

Onde $\Delta Y$ representa a variação na demanda de soja causada pelo aumento no custo de produção repassado integralmente aos preços, e $\Delta X$ representa o vetor de variações no VBP setorial. Neste exercício contrafactual foi adotada a elasticidade preço brasileira da demanda de soja calculado por Costa, Xia e Rosson (2007) e Simões (2008). Embora a exportação de soja em grão represente grande parte da demanda pelo produto nacional, a elasticidade preço da demanda por importações de soja em grão dos principais importadores são próximos àquela da economia brasileira.

Para avaliação dos impactos diretos na geração de emprego foram calculados os coeficientes setoriais de emprego, assim definidos:

$$
C E M P=\frac{E M P}{X}
$$

Onde $E M P$ é um vetor que define o número de pessoas ocupadas em cada setor da economia, e $X$ é o vetor da produção total nos respectivos setores. O cálculo dos impactos na geração de valor adicionado bruto também fez uso da mesma metodologia:

$$
C V A B=\frac{V A B}{X}
$$

Onde $V A B$ é o vetor referente ao valor adicionado bruto gerado nos diferentes setores da economia. A partir das equações (11) e (12) foi possível calcular os impactos diretos e indiretos na geração de emprego e valor adicionado bruto, causados pelas transformações nos setores de soja e fertilizantes tal qual simulados nos "choques". A metodologia empregada nesta tarefa é a seguinte: 


$$
\Delta E M P=\hat{V}^{e m p} L \Delta X^{*}
$$

Onde $\hat{V}^{e m p}$ é uma matriz diagonal $(n \times n)$, na qual os elementos da diagonal correspondem aos coeficientes de emprego obtidos através da equação (11) aplicada aos demais setores. O vetor $\Delta X_{(n x 1)}^{*}$ expressa os impactos sobre o VBP setorial, causados pelos "choques" avaliados nas expressões (9) e (10). O vetor $\Delta E M P(n \times 1)$ divulga o número absoluto de empregos gerados em cada setor. A soma das linhas deste vetor indica o total de empregos gerados na economia. Os cálculos do VAB adotam a mesma metodologia. O quadro abaixo apresenta os impactos em toda a economia resultantes do " $1^{\circ}$ choque" (setor de fertilizantes) e do " $2^{\circ}$ choque" (setor de soja em grão). A linha total corresponde à soma destes resultados.

Tabela 2 - Resultados do Modelo.

\begin{tabular}{lllll}
\multirow{3}{*}{ Cenários } & \multirow{2}{*}{ Setores } & \multicolumn{3}{c}{ Resultados } \\
\cline { 3 - 5 } & & $\mathrm{N}^{\circ}$ de empregos & $\mathrm{R} \$$ milhões & $\mathrm{R} \$$ milhões \\
\cline { 2 - 5 } & \multicolumn{1}{c}{$\Delta^{e m p}$} & $\Delta^{V A B}$ & $\Delta X$ \\
\hline \multirow{3}{*}{ Básico } & Fertilizantes & 232.384 & 7.985 & 9.035 \\
\cline { 2 - 5 } & Soja & -47.360 & -1.656 & -1.906 \\
\cline { 2 - 5 } & Total & 185.023 & 6.329 & 7.129 \\
\hline \multirow{3}{*}{ Competitivo } & Fertilizantes & 142.237 & 4.887 & 5.531 \\
\cline { 2 - 5 } & Soja & -23.636 & -802 & -932 \\
\cline { 2 - 5 } & Total & 118.601 & 4.085 & 4.608 \\
\hline \multirow{3}{*}{ Máximo } & Fertilizantes & 232.679 & 7.998 & 9.042 \\
\cline { 2 - 5 } & Soja & -258.118 & -9.550 & -11.024 \\
\cline { 2 - 5 } & Total & -25.439 & -1.552 & -1.982 \\
\hline
\end{tabular}

Fonte: Elaboração Própria.

\section{4 - AVALIAÇÃO DOS RESULTADOS E DISCUSSÃO}

Em 2006, a produtividade média das lavouras de soja no Brasil foi de 2.800 quilos por hectare. Conforme exposto, cada tonelada de soja colhida arranca do solo 80 quilos de nitrogênio. Com base na produtividade média da soja e na recomendação de adubação, estima-se o consumo necessário de 810 quilos de ureia por hectare para reposição integral dos nutrientes arrancados na colheita. Quantidade que 
implica, considerando o preço médio da ureia no mercado nacional, no gasto de R \$390,00 por hectare de soja cultivado em 2006. Em comparação aos inoculantes, percebe-se que a via da FBN oferta a mesma quantidade de nutriente ao custo de $\mathrm{R} \$ 8,00$.

Assim sendo, estima-se que o uso dos inoculantes tenha proporcionado a redução do gasto com insumos no setor produtor de soja em R\$ 382,00 por hectare no ano de 2006. Porém, o impacto econômico dos inoculantes não pode ser medido somente através da multiplicação deste valor pelo total de área plantada de soja no mesmo ano. A análise desconsidera os impactos indiretos nas atividades relacionadas, assim como a propagação desses efeitos por toda a economia. Qual é, por exemplo, o impacto sobre a economia nacional da redução da produção de ureia? Tal problema é captura com uso da MIP.

Desse modo, a avaliação dos resultados procede em dois estágios. No primeiro momento os impactos sobre o valor bruto da produção $(\Delta X)$, emprego $(\Delta e m p)$ e valor adicionado bruto $(\Delta v a b)$ capturam o aumento na capacidade instalada nacional de fertilizantes nitrogenados. No segundo momento os indicadores traduzem os resultados do exercício contrafactual proposto para avaliar as consequências dos aumentos no custo da produção da soja. O resultado total avalia o impacto ao término dos dois estágios.

Dadas as proposições do cenário básico, o montante de adubos demandado pela substituição dos inoculantes por fertilizantes nitrogenados na cultura da soja equivale ao incremento de aproximadamente $800 \%$ no nível de produção nacional de amônia-ureia verificado no ano de 2006 . Porém, a adubação nitrogenada eleva o custo de produção por hectare e consequentemente reduz a competitividade internacional da soja brasileira. Esse impacto é capturado pelo exercício contrafactual que indica a redução de 47 mil empregos na economia, decorrentes da menor demanda por soja. O resultado total do cenário básico indica que a substituição dos inoculantes pelos fertilizantes nitrogenados na soja proporcionaria um incremento de 7 bilhões de reais no valor bruto da produção nacional, em valores de 2006, valor que corresponde à diferença entre o incremento no setor fertilizantes e a redução no setor produtor de soja em grão.

No cenário competitivo os impactos da substituição de insumos na cultura da soja são menores do que no cenário básico, embora a demanda por nitrogênio seja maior. Há redução também nos impactos avaliados pelo exercício contrafactual. Nota-se que o incremento no nível de produção por hectare ocorre com gastos menores do que os realizados no cenário básico. A eficiência de $50 \%$ da FBN de nitrogênio 
impede a destruição de quase 24 mil postos de trabalho no setor da soja. No total, o incremento no valor bruto da produção nacional corresponde à R $\$ 4.608$ milhões.

Os resultados do cenário máximo reforçam a hipótese central do trabalho. Sem o uso de inoculantes a produção brasileira de soja não seria economicamente viável no longo prazo por culpa dos gastos com os fertilizantes nitrogenados. Conforme abordado anteriormente, o nitrogênio é um elemento essencial ao crescimento das plantas. Por esse motivo, plantas com maior nível de produção demandam maior quantidade de nitrogênio. Programas de melhoramento genético das cultivares brasileiras de soja podem alterar a capacidade de absorção dos nutrientes das plantas, no entanto não alteram a quantidade de nutrientes requeridos.

No cenário máximo o nível de produção da soja exige a adubação de quase duas toneladas de ureia por hectare cultivado. Porém, adota-se um incremento na capacidade instalada nacional de nitrogenados idêntico aquele verificado no cenário básico. O intuito é demonstrar que a dependência nacional de fertilizantes importados é um fenômeno dinâmico. O resultado total obtido no cenário máximo indica o fechamento de 25.439 postos de trabalho, e a redução de quase R 2 bilhões no valor bruto da produção nacional.

Neste quadro, os impactos econômicos positivos do incremento na produção nacional de fertilizantes nitrogenados são superados pelo choque negativo na demanda de soja. Parte deste resultado é devido à diferença entre os coeficientes de valor adicionado bruto e emprego daqueles setores. Em valores de 2006, para cada R\$ 1 milhão alocado na produção de soja em grão foram gerados 12 postos de trabalho contra apenas 2 no setor de fertilizantes. Com relação à geração direta de VAB, de cada R\$ 1 milhão aplicado na produção de soja o equivalente à $\mathrm{R} \$ 600$ mil retornaram para a sociedade em forma de renda contra R \$ 240 mil no setor de fertilizantes. 
Embora os resultados representem o aumento esperado no valor total da produção causado pela substituição dos inoculantes na cultura da soja, a continuidade da inoculação não signifíca que esta riqueza deixou de ser criada pela economia nacional. O argumento chave que lastreia a afirmação acima reside na avaliação do coeficiente de valor adicionado bruto do setor produtor de soja. Mantido constante o valor total da produção do setor soja, o aumento no consumo intermediário correspondente à substituição dos inoculantes implica a redução no valor adicionado bruto deste setor . Desse modo, afirma-se que a expansão na capacidade instalada do setor de fertilizantes minerais corresponde à imobilização em capital físico de parte da renda gerada pelo setor produtor de soja. Por esse ângulo de ataque, os resultados do modelo podem ser interpretados como o impacto econômico dos inoculantes.

Não obstante os efeitos capturados na matriz insumo produto, fatores como a monetização de maiores quantidades de gás natural extraído das reservas nacionais e a redução da dependência de importações reforçam o conjunto de argumentos favoráveis à estratégia de expansão da produção de ureia. Nesse contexto, de fato, a não expansão da capacidade instalada no setor produtor de fertilizantes minerais representa a destruição de riqueza na economia nacional. Em defesa desta posição resgata-se o índice de queima de gás natural no país, principal insumo da produção de fertilizantes nitrogenados, que ultrapassa $40 \%$ da produção anual (Ferraro, 2010). Porém, em uma perspectiva evolucionária, cujo ponto central remete ao processo de destruição criativa, tais investimentos devem ser avaliados à luz do sistema setorial de produção dos fertilizantes nitrogenados e do "estado da arte" na área da nutrição vegetal.

No caso do setor produtor de soja, a substituição dos inoculantes por fertilizantes nitrogenados implica na redução da produtividade e consequente perda de competitividade no mercado internacional. Análises prospectivas dos efeitos da inoculação em demais culturas como o milho, o trigo e a cana de açúcar, indicam resultados semelhantes. De modo geral, tais elementos acenam para o esgotamento da trajetória tecnológica agrícola calcada no uso intensivo de fertilizantes minerais e incentivam a busca por tecnologias alternativas capazes de sustentar o nível de produção. No entanto, cabe ressaltar que, o resultado da competição tecnológica na área da nutrição vegetal, em prol dos fertilizantes minerais, não pode ser descrito como um fenômeno de aprisionamento em tecnologias inferiores. 


\section{5 - CONSIDERAÇÕES FINAIS}

As perspectivas para o crescimento da população mundial e da renda per capita em países em desenvolvimento reforçam a necessidade de aumentos no nível de produção e na qualidade dos alimentos. Contudo, os desafios que se impõem na realização destas tarefas são consideráveis. Paradoxalmente, alguns dos constrangimentos à expansão da produção de alimentos têm origem no próprio setor agrícola. Como por exemplo, a crescente demanda por biocombustíveis e a escassez de terras agricultáveis disponíveis.

As projeções de expansão na área cultivada com alimentos são insuficientes frente ao incremento esperado na demanda mundial. Nesse quadro, o aumento da produção sem a expansão da área cultivada destaca-se como única alternativa viável para atender às necessidades nutricionais da população no ano de 2050 (FAO, 2009b). Conforme demonstrado ao longo do trabalho, o melhoramento genético dos cultivares tem desempenhado papel central como plataforma para intensificação dos cultivos. No entanto, fenômenos como a emergência da biotecnologia moderna e o crescente debate em torno do nível de exploração dos recursos naturais foram capazes de questionar o modelo de produção agrícola intensivo em insumos químicos.

O avanço da biotecnologia agrícola não compreende o desenvolvimento de plantas que dispensem a nutrição vegetal. Pelo contrário, variedades de alto rendimento demandam maiores quantidades de nutrientes. Nesses termos, o presente trabalhou buscou questionar a exclusividade dos adubos químicos enquanto fonte provedora de nutrientes às plantas. Para além dos impactos ambientais e do consumo elevado de recursos naturais empregados na fabricação dos fertilizantes sintéticos, a trajetória tecnológica da agricultura calcada no uso de insumos químicos dá sinais claros de esgotamento. No caso específico dos adubos nitrogenados, esforços concentrados para difusão de alternativas ao uso destes insumos vêm se tornando consenso nas interações sobre o tema.

A rota tecnológica dos insumos nitrogenados utiliza como matéria-prima básica subprodutos da indústria de combustíveis fósseis (gás natural, coque, etc). Estimativas indicam que cada tonelada de amônia (nitrogenado básico) fabricada corresponde à emissão de 1,6 toneladas de $\mathrm{CO}_{2}$ na atmosfera (MCT, 2010, pg.187). As perdas de nitrogênio (lixiviação e nitrificação) depositado no solo pelos adubos nitrogenados reduzem a eficiência agronômica do produto e exigem a aplicação de doses extras. Não 
obstante a elevação no custo de produção dos agricultores, a adubação extra de fertilizantes nitrogenados repercute em outros segmentos da sociedade.

A quantidade de nitrogênio extra não absorvido pelas plantas permanece no solo por pouco tempo. $\mathrm{O}$ nitrogênio imobilizado é então convertido em nitratos que são "lavados" pelas águas das chuvas ou pelo sistema de irrigação. $\mathrm{O}$ destino destes líquidos é o lençol freático mais próximo. A contaminação de lençóis freáticos por nitratos pode causar mortandade de peixes e impactar diretamente na saúde da população. Os efeitos negativos do nitrato sobre a saúde, subproduto do fertilizante nitrogenado depositado no solo, são abordados há muito tempo.

Os inoculantes, por sua vez, possuem uma estrutura de produção limpa e intensiva apenas em conhecimento. Quando depositados no solo, além da fixação biológica do nitrogênio, os inoculantes contribuem para o incremento da matéria orgânica. Desse modo, fortalecem a fertilidade natural do solo e sustentam incrementos contínuos no nível de produção. Não por acaso, se recomenda que a recuperação de pastagens degradadas seja feita mediante a plantação de soja inoculada. Do ponto de vista da competitividade da produção, o sucesso da inoculação na soja brasileira serve de estímulo para a difusão deste produto para demais culturas como o milho, o trigo e o feijão. Um grande avanço nesta direção reside na ampliação do conhecimento comum sobre os produtos da biotecnologia moderna.

\section{Bibliografia}

ANDA. Anuário Estatístico do Setor de Fertilizantes. São Paulo: ANDA, 2006.

ANDA. Anuário Estatístico do Setor de Fertilizantes. São Paulo: ANDA, 2009.

BIOFAG. Biofertilizantes em Iberoamérica: visión técnica, científica y empresarial. Madrid: Red Iberoamericana de biofertilizantes microbianos para la agricultura, 2008. Mimeo.

CANHOS, W.P.; MANFIO, G.P. Recursos Microbiológicos para biotecnologia. In SILVEIRA, J.M.F.J.; DAL POZ, M.E.; ASSAD, A.L.(orgs.) Biotecnologia e recursos genéticos: Dimensões e oportunidades para o Brasil. Campinas, UNICAMP, Instituto de Economia-FINEP, 2004.

COSTA, R;XIA, Y.;ROSSON,P. An assessment of the global soybean industry: an application of stochastic equilibrium displacement model. Alabama, Mobile, Agricultural Economics Association Meeting, 2007.

DOBEREINER, J. Biological nitrogen fixation in the tropics: social and economic contributions. Soil biology and chemistry, Vol.29, 1997. 
FAO. The technology challenge. Roma: High-Level Expert Forum, 2009b. Disponível em: http://www.fao.org/wsfs/forum2050/wsfs-forum/en/.

FAO; IFA. Los fertilizantes y su uso. Paris: International Fertilizer Association, 2006.

FURTUOSO, M.C.O.; GUILHOTO, J.J.M. Estimativa e mensuração do Produto Interno Bruto do agronegócio da economia brasileira, 1994 a 2000. Revista Brasileira de Economia e Sociologia Rural.Vol.41, 2003.

GAN,Y.;STULEN,I.;POSTHUMUS,F. Effects of N management on growth, N2 fixation and yield of soybean. Nutrient Cycling in Agroeconsystems, Vol.62, 2002.

GUILHOTO,J.J.M. et al.PIB da agricultura familiar: Brasil- Estados. Brasília: Ministério do Desenvolvimento Agrário, 2007.

GUILHOTO, J.J.M.; CAMARGO, F.S.; IMORI,D.; INOMATA,S. National Input-Outpu Table o Brazil. Asian International Input-Output Series, Vol.71, 2008.

GUILHOTO,J.J.M.; SESSO FILHO, U. Estimação da Matriz Insumo-Produto a partir de dados preliminares das Contas Nacionais. Economia Aplicada, Vol.9, Abril, 2005.

HUNGRIA,M. Microrganismos de Importância Agrícola. Brasília: EMBRAPA, 1994.

HUNGRIA,M.;CAMPO,R.J.;MENDES,I.C. A importância do processo de fixação biológica do nitrogênio para a cultura da soja: componente essencial para a competitividade do produto brasileiro. Londrina: Embrapa Soja, 2007. mimeo.

HUNGRIA,M. et al. Nitrogen Nutrition of soybean in Brazil: contributions of N2 fixation and of N fertilizer to grain yield. Canandian Journal of Plant nutrition science, Vol.86, 2006.

IBGE. Série Relatórios Metodológicos: Sistema de Contas Nacionais. Rio de Janeiro: Instituto Brasileiro de Geografia e Estatística, 2008.

IFA. The Chemical fertilizer industry in China: A review and its outlook. Paris: International Fertilizer Association, 2009.

IFA. Indonesia National Fertilizer Industry: Current situation and future development. Paris: International Fertilizer Association, 2007.

IPT. Tecnologia de Produção de Fertilizantes. São Paulo: Instituto de Pesquisas Tecnológicas, 1990.

KURZ, H.D.; SALVADORI, N. Classical Roots of Input-Output Analysis: a shirt Account of its Long Prehistory. Economic Systems Research.Vol.12, Junho, 2000.

MCTI, Segunda Comunicação Nacional do Brasil à Convenção Quadro das Nações Unidas sobre 
Mudança no Clima. Brasília: Ministério da Ciência e Tecnologia, 2010.

MILLER, R.; BLAIR, P. Input-Output Analysis. Cambridge: Cambridge University Press, 2009.

NOVAIS, F. (org). Fertilidade do Solo. Viçosa: Sociedade Brasileira de Ciência do Solo, 2007.

SILVEIRA, J.M.F.J.; BORGES, I.C.; BUAINAIN, A.M.; Biotecnologia e Agricultura: da ciência e tecnologia aos impactos na inovação. São Paulo em perspectiva, Vol.19, 2005.

SILVEIRA, J.M.F.J.; BORGES, I.C.; FONSECA, M.G.D. Biotecnologia e desenvolvimento de mercados: novos desafios, novos conceitos. In RAMOS, P. (org.) Dimensões do Agronegócio Brasileiro. Brasília: Ministério do Desenvolvimento Agrário, 2007.

SILVEIRA, J.M.F.J.; DAL POZ, M.E.; ASSAD, A.L.(orgs.) Biotecnologia e recursos genéticos: Dimensões e oportunidades para o Brasil. Campinas, UNICAMP, Instituto de Economia-FINEP, 2004.

SIMÕES, D.C. Regras, normas e padrões no comércio internacional: o Protocolo de Cartagena sobre biossegurança e seus efeitos potenciais para o Brasil. Piracicaba, ESALQ-USP, Dissertação de Mestrado, 2008.

UNKOVICH,J.M.; PATE,J.S. An appraisal of recent field measurement of symbiotic N2 fixation by annual legumes. Fields Crop Research, Vol.65, 2000.

VAN KESSEL,C.; HARTLEY,C. Agricultural management of grain legumes: has it led to an increase in nitrogen fixation. Field Crops Research, Vol.65, 2000. 